(see table). ${ }^{12}$ None of these children showed clinical signs of dehydration. Symptoms associated with hyponatraemia were not reported, but four children with a serum sodium below $125 \mathrm{mmol} / \mathrm{l}$ died during one study.

We also found several case series in which patients with respiratory infections developed hyponatraemia, of which some were symptomatic (table). ${ }^{5}$ These patients were all successfully treated with fluid restriction.

\section{Comment}

We found data to suggest that giving increased fluids to patients with respiratory infections may cause harm. To date there are no randomised controlled trials to provide definitive evidence, and these need to be done. Until we have this evidence, we should be cautious about universally recommending increased fluids to patients, especially those with infections of the lower respiratory tract.
We thank Ruth Foxlee, Cochrane Acute Respiratory Infections Group Trials Search Coordinator, for performing the searches. Contributors: CBDM conceived and supervised the study, and prepared the manuscript. MPBG and SMM undertook the search, and contributed to writing the manuscript. CBDM is the guarantor for the study.

Funding: The post of academic research registrar is funded by General Practice Education and Training.

Competing interests: None declared.

1 Shann F, Germer S. Hyponatraemia associated with pneumonia or bacterial meningitis. Arch Dis Child 1985;60:963-6.

Dhawan A, Narang A, Singhi S. Hyponatraemia and the inappropriate ADH syndrome in pneumonia. Ann Trop Paediatr 1992;12:455-62.

3 Dreyfuss D, Leviel F, Paillard M, Rahmani J, Coste F. Acute infectious pneumonia is accompanied by latent vasopressin-dependent impairment of renal water excretion. Am Rev Respir Dis 1988;138:583-9.

4 Gozal D, Colin AA, Jaffe M, Hochberg Z. Water, electrolyte, and endocrine homeostasis in infants with bronchiolitis. Pediatr Res 1990;27:204-9.

Rivers RP, Forsling ML, Olver RP. Inappropriate secretion of antidiuretic hormone in infants with respiratory infections. Arch Dis Child 1981;56:358-63.

doi 10.1136/bmj.38028.627593.BE

\title{
Effect of statin treatment for familial hypercholesterolaemia on life assurance: results of consecutive surveys in 1990 and 2002
}

\author{
H A W Neil, T Hammond, D Mant, S E Humphries Topic: 183;163
}

Oxford Centre for Diabetes,

Endocrinology and Metabolism,

Churchill Hospital,

Oxford OX3 7HJ

H A W Neil

honorary consultant

physician

Division of Public

Health and Primary

Health Care

Institute of Health

Sciences, University

of Oxford, Oxford

OX3 7LF

T Hammond

research assistant

D Mant

professor of general

practice

Centre for

Cardiovascular

Genetics, British

Heart Foundation

Laboratories, Royal

Free and University

College London

Medical School,

London WC1E 6JJ

S E Humphries

professor of

cardiovascular

genetics

Correspondence to:

H A W Neil

andrew.neil@

wolfson.ox.ac.uk

BMJ 2004;328:500-1
One of the concerns often raised about genetic testing is the possibility that a positive result (or even disclosing that the test has been taken) may result in difficulty in obtaining life assurance. Currently the UK insurance industry has declared a moratorium on requiring genetic tests from applicants, ${ }^{1}$ but since DNA based tests offer a definitive, highly specific diagnosis they are likely eventually to replace less specific clinical diagnostic criteria for many inherited disorders. Early, presymptomatic treatment may increase life expectancy by preventing or reducing the risk of developing the disease or associated complications. However, if life assurance policy premiums do not adequately reflect the reduction in mortality with treatment relatives of affected probands may be deterred from being tested. We examined how life assurance companies have responded to the improvement in the prognosis of heterozygous familial hypercholesterolaemia with statin treatment. ${ }^{2}$

Familial hypercholesterolaemia is an autosomal dominant disorder, inherited on average by one in two children of an affected parent. The prevalence in the United Kingdom is about 1:500, but at least three quarters of cases remain undiagnosed. ${ }^{3}$ It is usually caused by mutations in the gene for the low density lipoprotein (LDL) receptor that result in accumulation of plasma cholesterol and substantially increased coronary mortality. Without effective treatment the cumulative risk of a coronary event is at least $50 \%$ in men and 30\% in women by the age of 60 years. ${ }^{4}$ With statin treatment, however, the standardised mortality ratio for coronary heart disease for such patients aged
20-59 years has more than halved over the past decade. $^{2}$

\section{Participants, methods, and results}

We conducted a survey of 41 life assurance companies in $1990^{5}$ and repeated it in 2002 by sending the same questionnaire to 26 companies still underwriting term life assurance. They were asked to assess a fictional proposal for a 20 year policy (paying benefit only on death) by applying an excess mortality rating defined as the percentage increase over the assumed rate of mortality. In the follow up survey companies were asked to assess the rating before and after statin treatment. The applicant was a normotensive $(120 / 80 \mathrm{~mm}$ $\mathrm{Hg}$ ), non-smoking, 30 year old man taking no medication, with a body mass index of $22.1 \mathrm{~kg} / \mathrm{m}^{2}$ and a normal resting electrocardiogram, whose father had had a non-fatal myocardial infarction aged 45 years. He had no other family history of heart disease, other medical history of note, or tendon xanthomata on examination. The results of the lipid profile $(\mathrm{mmol} / \mathrm{l})$ were total cholesterol 11.4, high density lipoprotein (HDL) cholesterol 1.7, triglycerides 1.3, and calculated LDL cholesterol 9.1; and the presumptive diagnosis was familial hypercholesterolaemia. On treatment with atorvastatin $80 \mathrm{mg}$ daily his total cholesterol concentration was $6.2 \mathrm{mmol} / \mathrm{l}$ (compared with $10.7 \mathrm{mmol} / \mathrm{l}$ on cholestyramine prescribed in 1990).

The figure shows the excess mortality ratings applied. Because two companies would assess proposals only from patients receiving statin treatment statistical comparisons were restricted to 24 companies. The 


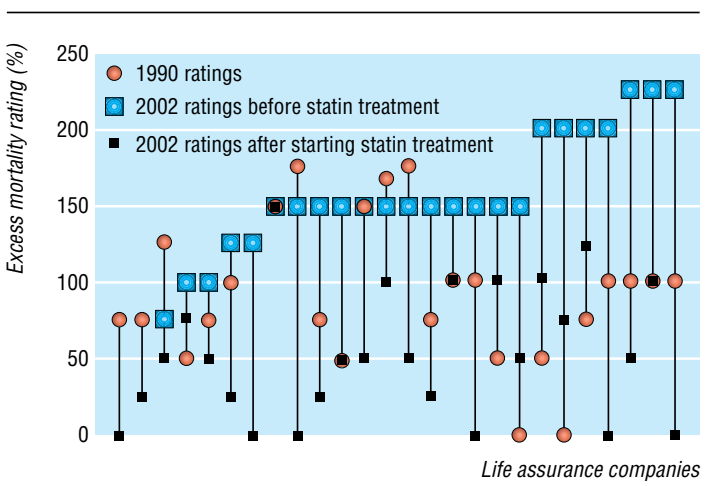

Percentage excess mortality ratings applied by life assurance companies in 1990 and 2002, before and after starting statin treatment

mean excess rating increased from 89\% (SD 52) in 1990 to $158 \%$ (SD 40) in 2002 (difference 69\%, 95\% confidence interval 41 to $97 ; \mathrm{P}<0.000$, paired $t$ test), but fell to $56 \%$ (SD 43) on treatment $(102 \%, 79$ to 126 ; $\mathrm{P}<0.000$ ), which was $33 \%$ lower (5 to $61 ; \mathrm{P}=0.022$ ) than the original rating in 1990.

\section{Comment}

The increase in mortality rating in the second survey, together with the substantial reduction in the excess applied to patients taking statins show that underwriters now assess risk more realistically and recognise that the prognosis for familial hypercholesterolaemia has improved with more effective treatment. ${ }^{2}$ Nevertheless variability in the rating applied was considerable, and patients could usefully be advised to shop around for the most competitive premium. The results of the survey, however, are reassuring and should encourage relatives of probands to be tested rather than being deterred by concerns about life assurance.

We thank the life assurance companies for participating in the study.

Contributors: HAWN and DM designed the study, TH conducted the survey, HAWN undertook the analysis, SEH and HAWN wrote the paper. All authors participated in the interpretation and critical revision of the paper. HAWN is the guarantor.

Funding: This work was supported by a grant from the British Heart Foundation (PG2000/015) and was carried out in part with support from the Department of Health and the Department of Trade and Industry for the IDEAS Genetics Knowledge Park.

Competing interests: None declared.

1 Mayor S. UK insurers agree five-year ban on using genetic tests. BMJ 2001;323:1021.

2 Scientific Steering Committee on behalf of the Simon Broome Register Group. Mortality in treated heterozygous familial hypercholesterolaemia: implications for clinical management. Atherosclerosis 1999;142:105-12.

3 Neil HAW, Hammond T, Huxley R, Matthews DR, Humphries SE. Extent of underdiagnosis of familial hypercholesterolaemia in routine practice: prospective registry study. BMJ 2000;321:148.

4 Stone NJ, Levy RI, Fredrickson DS, Verter J. Coronary artery disease in 116 kindred with familial type II hyperlipoproteinaemia. Circulation 1974:49:476-488.

5 Neil HAW, Mant D. Cholesterol screening and life assurance. BMJ 1991;302:891-3.

(Accepted 2 October)

\title{
Length of patient's monologue, rate of completion, and relation to other components of the clinical encounter: observational intervention study in primary care
}

\author{
Israel Rabinowitz, Rachel Luzzatti, Ada Tamir, Shmuel Reis
}

The patient's opening statement in a consultation (the patient's monologue) is an important part of history taking, and doctors are encouraged not to interrupt the patient-but they often do, ${ }^{12}$ probably because they think that the patient's monologue is time consuming. When uninterrupted, patients conclude their monologue in less than 30 seconds in primary care and about 90 seconds in consultant settings. ${ }^{1-5}$

We assessed encounters in primary care that included a new clinical problem, recording the length and rate of completion of patients' monologues before and after instructing doctors not to interrupt.

\section{Methods and results}

We recorded consecutive encounters between eight family physicians and their patients on two days in six family clinics in northern Israel. All doctors were videotaped on both days. They had been told that the study focused on the doctor-patient interaction. Patients were given this explanation via a written notice on the door of the consulting room and also orally by the doctor when required. At the start of the second day the doctors were handed a written note that said: "When the patient starts speaking, please do not interrupt him or her until you are satisfied that he or she has finished."

All practices had stable lists, and patients were seen by their regular doctors. The eight doctors were a convenience sample (five men; mean age 39.7 (range 35 to 44) years); all had completed the residency programme in family medicine. The sex and age of patients seen on days 1 and 2 was similar.

In total, 235 consultations (omitting two refusals) were recorded; 21 were excluded due to foreign languages, office procedures, and technical difficulties. Of 214 (91\%) encounters we viewed, 112 (52\%) involved a new clinical problem. We examined these for length of patient's monologue, whether the monologue was completed, performance and length of physical examination, ordering of accessory tests (or referrals to specialists), prescriptions, and total encounter time. Statistical analysis used $\chi^{2}$ and $t$ tests, with significance
Clalit Health Services and Department of Family Medicine, B Rappaport Faculty of Medicine Technion-Israel Institute of Technology, Haifa, Israel

Israel Rabinowitz family physician Rachel Luzzatt family physician Shmuel Reis family physician continued over BMJ 2004;328:501-2 